\title{
أفكار في السياسية عند جون لوك
}

\author{
م.د. نـماونـد علي العلوي \\ كالية الآداب / جامعة بـغداد
}

المقدهـة:

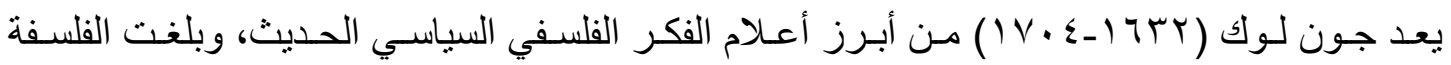
السياسية عند أوجها بمـا طرحهـ من أفكار فلسفية سياسية استوحاها مدن سبقه من الفلاسفة الذين تتـاولوا المفاهيم الفلسفية السياسية، وكذلك الاجتماعية و التي دارت حول مو اضيع السلطة و الدولة و المجتمع و السيادة و غير ها، إلا أن ميزة جون لوك في فلسفته السياسية أنه حصر الفكر الفلسفي السياسي في بحوثه بشكل مفصل ومتر ابط نظرياً وفكرياً، ووضع لها حلول و أسباب حسب رؤيته، و هذا لا يعني أنه لم يطلع على تراث سـابقيه

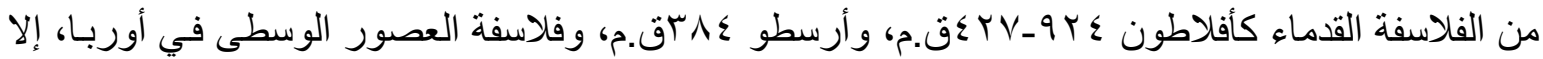
أن الفارق الزمني و الظروف التي عاثتها جون لوك استدعت أن يصو غ أفكارًا فلسفية مسبوكة بطسابع العصر وظروفه الثخصية واستحصالاته الثقافية الفلسفية وكذلك جهوده الفرديـة في أكمال مـا يريد بحثه ومـا يهدف إلى الخروج بنتائج وقرار ات فلسفية سياسية، كمفهوم السيادة و العقد الاجتماعي وغير ها من المفاهيم التي بحثنا عنهـا في دراستنا المتو اضـعة هذه. علمـاً بأنتـا استندنا في دراستتنا على المصــادر و المر اجـع ذات الصـلة الموضوعية في الأفكار التي تم استعر اضها في البحث مساهمة منو اضعة في خدمة المعرفة الإنسانية. و اقتضت طبيعة البحث أن ينقسم إلى مبحثين أوله ويدور حول العقد الاجتمـاعي والسيادة، إضـافة إلى الحكومـة وأنو اعهـا فضـلاً عن انحلال الحكومـات، في حين يتتـاول المبحث الثاني مو اضيع الطغيـان و الغلبـة وكذلك السلطة وأنو اعها، فضلاً عن السلطة الأبوية، ثم الخاتمة .

\section{المبحث الأول- لمات عن العقد الاجتهاءي ودوره في نشوء الهكوهات وأسباب انحلاها}

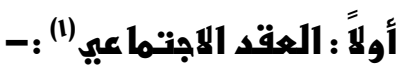

جون لوك(r) صـور حالـة الطبيعة الأولى على أنها حالـة سـلام وطمأنينـة وأمـان يسودها حسن النيـة، و المعونـة المتبادلة، وكذلك المحافظة على الذات، وأن الناس كانو ا يعيشون أحراراً منسـاوين لا يحكمه إلا

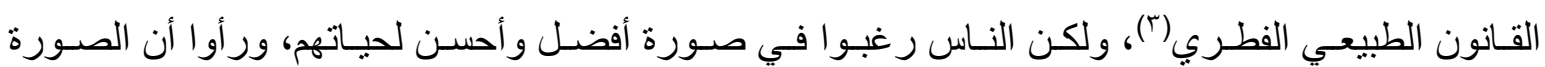
المطلوبة تتحقق بانتقال المجتمع الطبيعي إلى مجتمع فيه تنظيم يتفق عليه مجتمع بغير سلطة إلى مجتمع فيـه

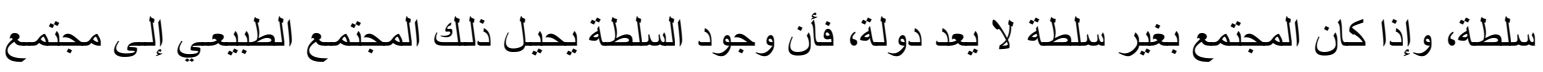
سياسي أو إلى دولة(؛)، إذ يقول جون لوك في ذلك : أن حالة الطبيعة يحكمها قانون الطبيعة، فينبغي أن لا يوقع أحد منهم ضرراً على صاحبه أو حريته وممتلكاته، لأن خالق البشر صانع واحد قدير على كل شيء لا تحد حكمته، و هم عبيد لرب واحد عظيم بثهم في الأرض بإر ادته لكي يقومو ا على شؤونه لا شؤونهم (*)، ومن

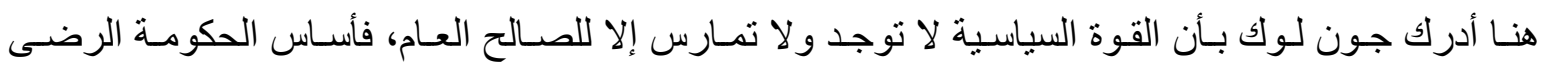

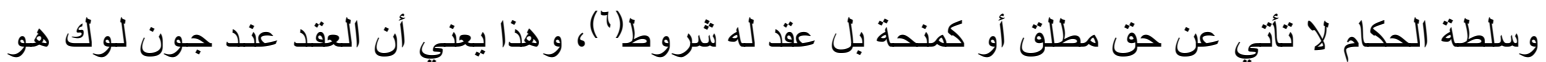


تعاقد هدفه الثعب من جهة والملك من جهة أخرى، وليس طرفاه واحد كما ذهب إلى ذلك ((تومـاس هوبز

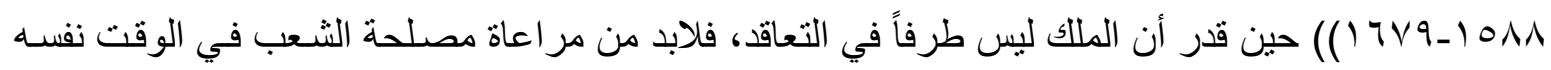
كي تتو ازن المعادلة بين السلطة وحقوق الناس الطبيعية(')، كما يرى لوك أيضاً أن الإنسان يولا حراً ومسـاوياً لأقر انه، وله الحق بالتمتع بممتلكاته وبجميع الحقوق الطبيعية، كما له الحق في دفع عدوان الآخرين على هذه الحقوق، وإنز ال بمن يقترف جرماً أو تعدياً على ماله، وكذلك أنزال العقوبة على مخالفي العقد (^). يتضح مما تقدم أن الجزء المتتازل عنه ضـرورة لازمـة لإقامـة السلطات العامـة وهو في قدره يوازي

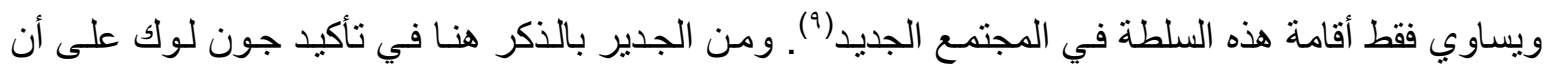
الهيئة التشريعية في الدولة هي صاحبة السلطة العليا في البلاد، وهذه السلطة في رأيه سلطة تخويلية ملتزمـة بتحقيق الأهداف التي قام المجتمع أصلاً من أجلها، و هكذا أعطى الثعب حق الاحتفاظ بالسلطة العليا التي وهي

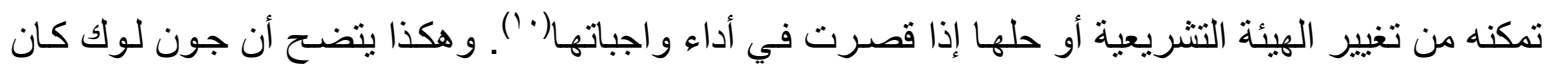
يدافع عن نظام الحكم الدستوري، وبذلك يكون تفكيره السياسي أكثر نضوجاً من تفكير هوبز، ثم أنه يفرق بين الحكومة والدولة، ويؤمن بقوة تقف ور اء الحكومة وتراقب أعمالها وهو الشعب، ومعنى هذا أنه يرى أن بقاء الحاكم في منصبه منوقف على أر ادة الثعب ومو اقفه، فسيادة الدولة ليس معناها سيادة الحكم كما يزعم هوبز، ولكن أر ادة الثعب تسنطيع أن تضع حدوداً لإر ادة الحاكم و لأعماله(' ')، وبذللك يمكننا القول أن للعقل الإنساني آفاق و اسعة كالموجود عند توماس هوبز وجون لوك و أنها لم تكن مجرد أحلام هائمة أو خيالات متر اقصة في آفاق العقل الإنساني، و إنما هي حقائق كفيلة بتطوير الزمن وصيرورة الحياة، فلهذا كله تم استخر اج قو انين

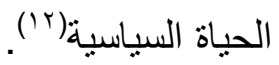

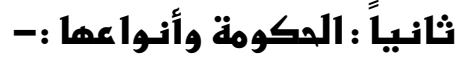

أعتبر جون لوك الحكومة(r)، على أنها حادث أقل أهمية من العهد الأصلي (العقد الاجتمـاعي) الذي يصنع مجتمعاً مدنياً ('). حيث أنه يذهب إلى تأيبد فكرة التقسيم الثلاثي التقليدي في نظرتهه السياسية، كمـا وأنه يؤيد من جهة أخرى فكرة الحكومة المختلطة، بشرط أن برغب فيها الثـعب ويو افق عليها، والر أي عنده بـأن قوة الجماعة تتركز في أكثرية الثعب و التي تمارس بطرق مختلفة، واستناداً إلى ما تقدم فـأن جون لوك يتخذ من طريقة ممارسة هذه القوة كمعيار أساس لأقامة تقسيمه للحكومات، فقد تمـارس عن طريق أكثريـة الثعب مباشرة ((حكومة ديمقر اطية)) وقد تمارس من خلال صفوة ممتازة من النـاس ((حكومـة أولجاريـة))، وأخيراً قد تمـارس مـن خـلال شـخص واحد ((حكومـة ملكيـة))، وقد تكون ور اثيـة أو ملكيـة بالانتخـاب طول حيـاة الملك(0). و هذا يعني بانه يستطيع وله الحق بتعيين خلف له عن طريق الأكثرية لاى وفاته.

و هكذا نؤلف من هذه الأشكال أشكالاً أخرى مركبة أو مختلفة، فإذا كانت الأكثريـة قد خلعت السلطة التشريعية فيتعين الأمر على شخص أو أكثر من شخص مدى حياته أو لمدة معينة، بحيث تعود السلطة العليا إليها، وللجماعة حق التصرف بها من جديد وخلعها على من شـاءت، ومحدثه بذلك شكلاً حكوميـاً جديداً (1). ولما كان شكل الحكومة يتوقف على السلطة العليا وهي السلطة التشريعية إذ يستحيل تصور سلطة دنيا تملي الأو امر على سلطة عليا أو تضع القوانين سلطة غير السلطة العليا لشكل الحكومة المرتبطة بمقررات السلطة 
التشريعية، إذاً الدولة عند جون لوك أصبحت عبـارة عن أداة توفر للأفراد النظـام والاستقرار والسـلام والذي يمكنهم من تحقيق أهدافهم الخاصة، و أهم ما ينبغي للدولة هو أن تحافظ على حق الأفر اد في الملكية، مع عدم

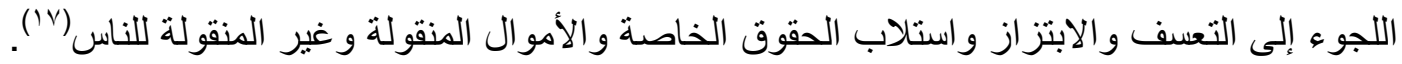

\section{نالثاً : السيادة : -}

تعد السيادة من المفاهيم المهمة في فلسفة جون لوك السياسية إذ أن للدولة ثلاثة أركان غاية في الأهمية و هي الأمة أو لاً تليها السيادة ثانياً، ثم الإقليم، وأن مفهوم السيادة كان قد أنتق من أصل لاتيني هو

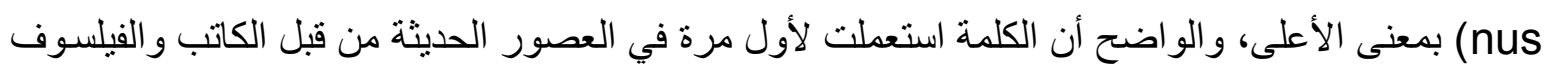

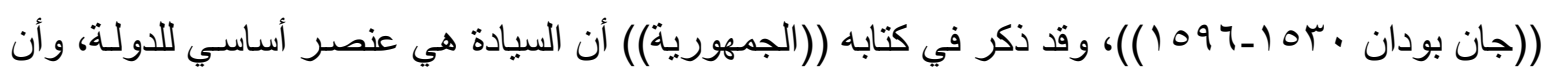
صاحب السلطة الثر عي الملك له مطلق السيادة و لا يشاركه فيها أحد(^^)، ونتجلى سيادة الدولة في معنيين :

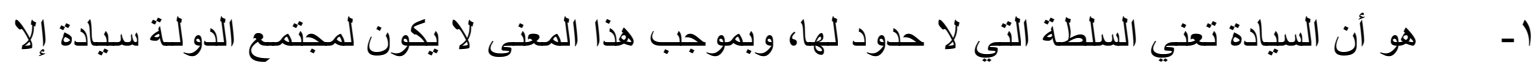
إذا كان يملك السلطة العليا الكاملة و غير المحدودة، أو بتعبير آخر يجب أن تكون سلطته لا حدود لها. r- المعنى الثاني: وهي أن السيادة بمعنى الاستقلال وهذا المعنى بدوره يثتمل على عنصرين مهمين غير منفصلين أحدهما سلبي و الآخر إيجابي(19). وللسيادة أيضاً وجهان :

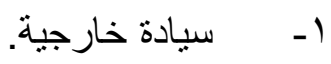

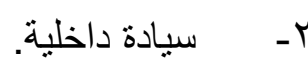

فالسيادة الخارجية ويقصد بها عدم خضوع الدولة لدولة أجنبية ذلك فيما عدا ما تعقده الدولة من اتفاقات دوليـة ـ و هذه الاتفاقـات أنمـا هي مظهر مـن مظـاهر سيادة الدولـة ـ فمـن الأمسور المتفق عليهـا أن السيادة

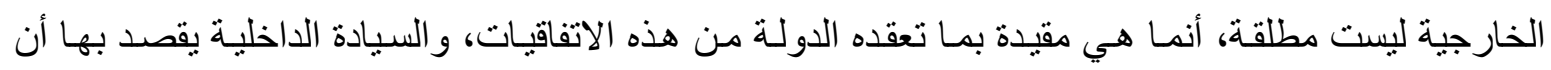
للاولة سلطة لا تعلو ها سلطة أخرى في ميدان نشـاطها داخل الدولة، أي في علاقاتها بـالأفر اد أو الجماعات

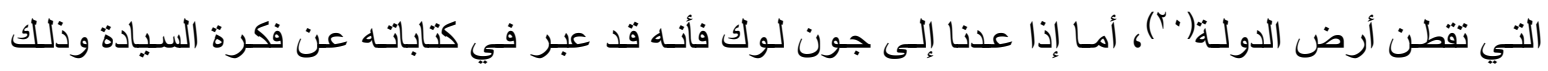

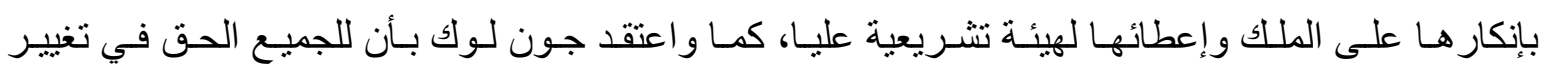
الحكومات إذا ما شعر الشعب بأنه محروم من حقوقه المدنية(r). رابـعاً: : انسهلال الهكومات :-

يتحدث جون لوك عن انحلال الحكومات إذ يقول : أن ما يكون الأمة الواحدة ويخرج بالناس عن طور الطبيعة المفكلك الأوصال ويجعل منهما مجتمعاً سياسياً واحداً هو الاتفاق بين الفرد و أقر انه على التكتل و العمل لهل

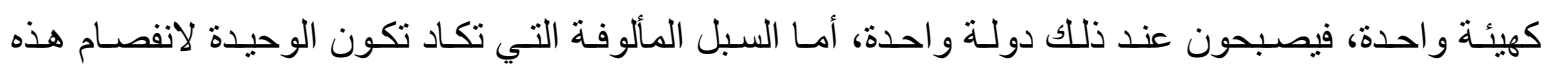
الوحدة، فهي سطوة قوة خارجية عليهم تؤدي إلى التغلب عليهم(rr)، وتنحل الدولة عندما يهمل صاحب السلطة التنفيذية مهمته وينبذها جانباً فيستحيل عندها تتفيذ القوانين التي سنت من قبل، ويؤدي ذلك لا محالـة إلى لى

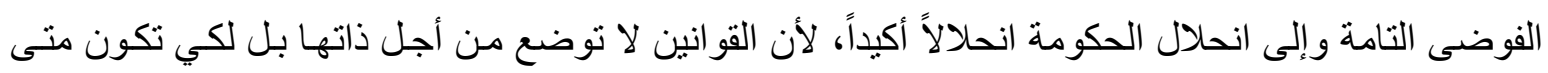


نفذت بمثابـة روابط المجتمع التي تثبت كل جزء مـن أجزاء المجتمع السياسي في موضعه الخـاص ليقوم بمهمته الخاصة ويصبح الشعب طائفة مشوشـة من البشر لا نظام لها و لا ارتباط بينها، وحيث لم يعد سبيل

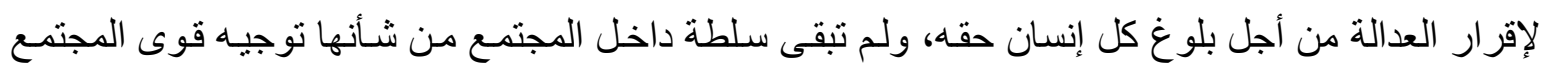

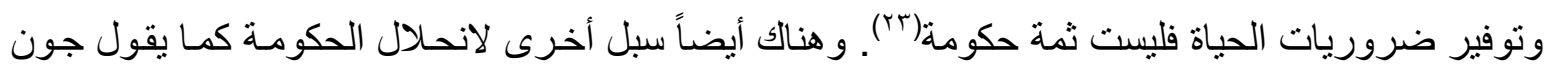

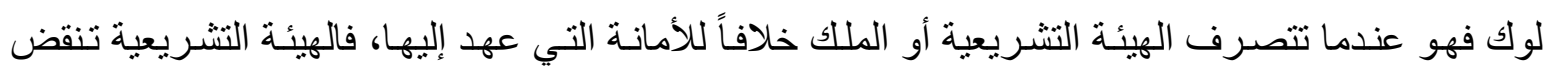
العهد الذي اؤتمنت عليه، عندما تسعى إلى السطوة على ملاك أحد رعيتها وتجعل من أعضائها أو من فئة من

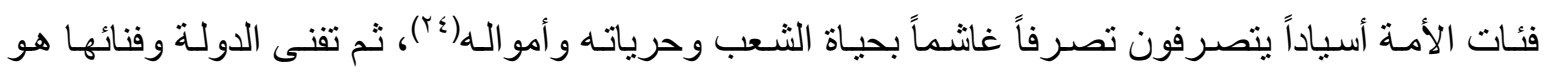
انعدام سيادتها واستقلالها بضمها طو عاً أو كر هـاً إلى دولة أو دول أخرى، وهنالك أمثلة على ذلك مثل فناء

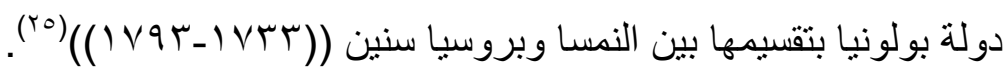

أن علة التحاق الناس بالمجتمع هي المحافظة على أمو الهم و الغرض من انتخاب هيئة تشريعية وتقليدها

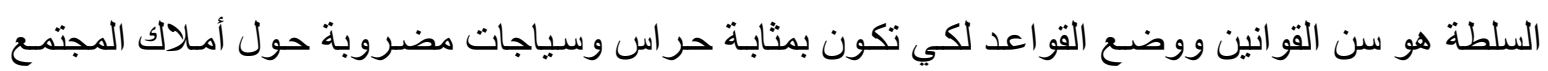

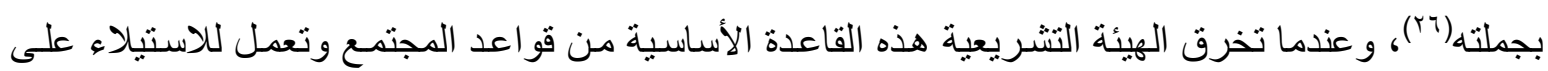
السلطة المطلقة على أرواح الناس وحرياتهم و أملاكهم، أو تسندها إلى هيئة أخرى أو طمعاً أو خوفاً أو جنونـاً

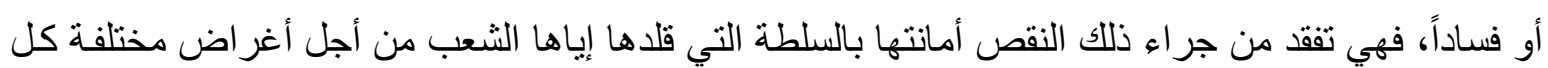

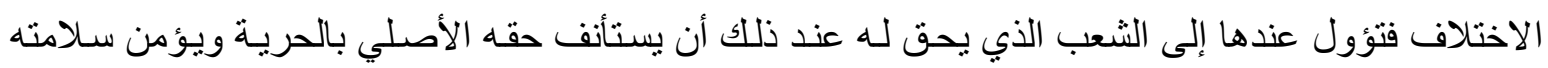
وبقاءه، وذلك بإقامة هيئة تشريعية جديدة(rV).

\section{المبحث الثاني- هظاهر السلطة عند جون لوك

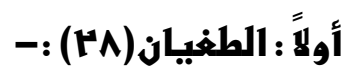

مفهوم الطغيان وبحسب جون لوك هو عبارة عن ممارسة السلطة التي لا تستند إلى أبي حق قط، والتي يستحيل أن تكون حقاً لأمرئ ما، وهو يقوم على استخدام امرئ ما السلطة التي وقعت إليهه من أجل مصلحته إنها

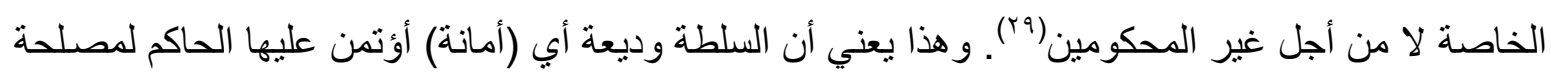

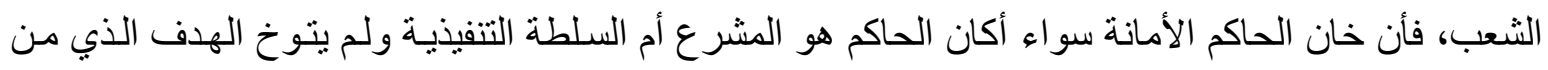

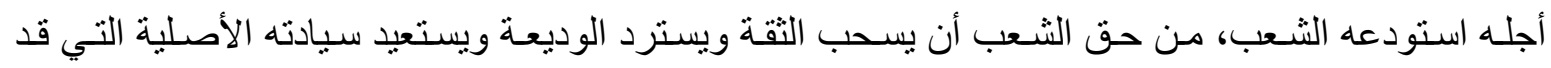
فوضى ممارستها لذلك الحكم(·r). فالحكومة تقوم على أسـاس العمل على رفاهيـة المجتمع ورعايـة مصسالحه، فإذا أهملت شـيئاً مـن ذلك وجب تغييرهـا وتزول الحكومـة أمـا بتغيير مركز السلطة التشـريعية وأمـا بعدم محافظتها على الأمانة وقد دلل جون لوك على هذه النظرية بأمثلة من تاريخ انكلتر ا. فتقوم الثورة ضد حكومـة

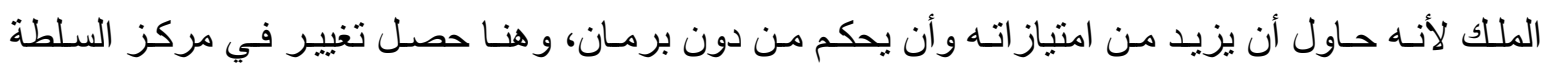

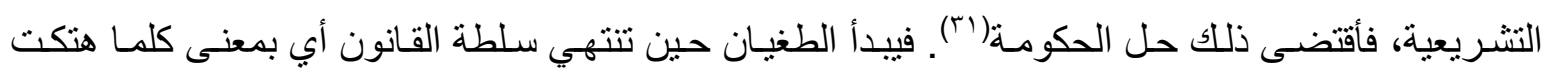

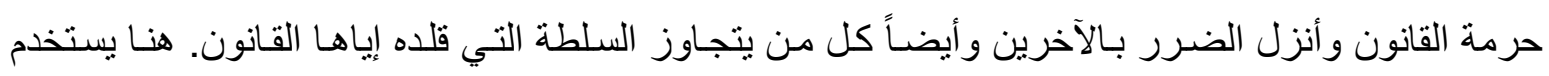

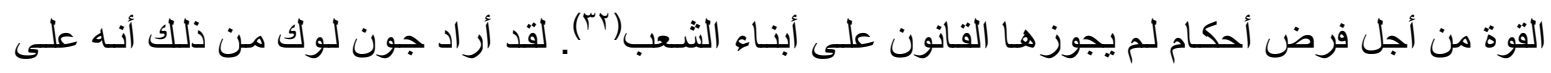

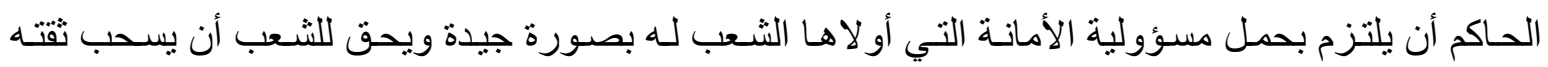


ويعطي الأمانة إلى من يستحقها، ويقول جون لوك في ذلك: لم يعد حاكماً بـالمعنى الأصيل إذا كان يتصرف

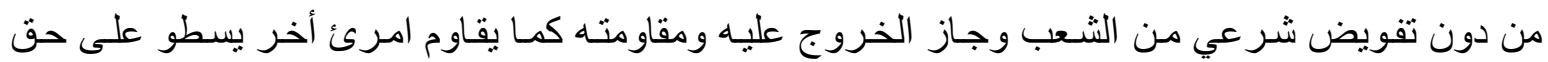

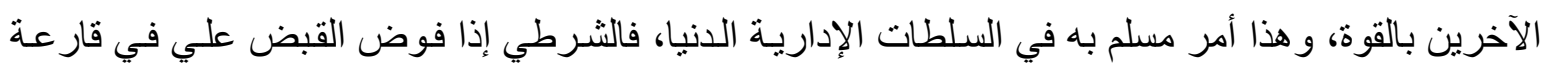

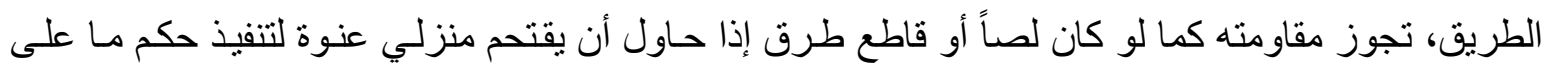
الرغم من علمي أن لديه مثل هذا الحكم ومثل هذه الصلاحية القانونية التي تخوله القبض علي خـارج البيت،

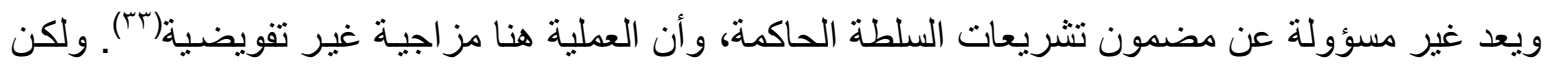
من هو ذلك الذي يقرر حل الحكومة والثورة عليها؟ يجيب جون لوك أن الثعب بأكمله هو الذي يقرر هذا، ومن ثم فلقد أعطى جون لوك حق الثورة للثعب تجاه الحكومة التي انحرفت وشذت عن الطريق الذي رسمه الثعب لهاب(ז)، فالطغيان نظام فاسد وأظهر أمكان أن تعمل الحكومات المستبدة في الخفاء وهي في الو اقع لا تعمل عادة إلا من وراء ستار التمويه و المظاهر الكاذبة(ror).

يعتقد جون لوك أن النظم السياسية يستحيل أن تبنى إلا على رضسى الثـعب، فالفتن التي يزخر بها تاريخ العالم، والتي تتجم عن طموح الحكام قد أدت إلى التغاضي عن هذا الرضا في غمرة الحرب التي تؤلف جانباً مهماً من تاريخ البشر، لذلك خلط عدد من الناس بين قوة السلاح ورضا الثـعب، فعدوا الغلبة أصلاً من أصول الحكم، ولكن العلاقة بين الغلبة وتأسيس حكومة من الحكومـات كتقويض بنيان ما وتشييد بنيان جديدة

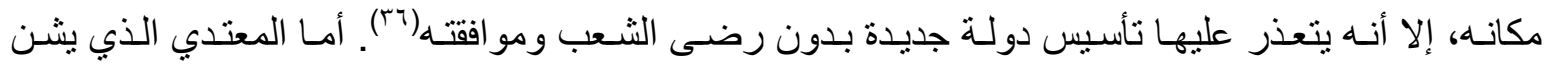

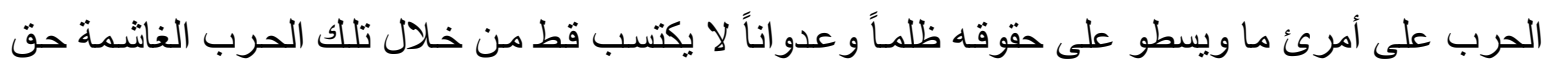
التسلط على المغلوب، فأمر يسلم به في الحال كل من يسلم أنه ليس من اللصوص و القر اصنة لهم الحق في التسلط على كل من يمكنهم بأسهم أن يسيطروا عليه، وأن الوعود التي تتنزع بـالقوة غير المشروعة لا تلزم أصحابها. لنفرض أن لصاً ما أقتحم منزلي و أرغمني على أمضاء ((صك)) يقضـي بتحويل أملاكي له، وهو لهو

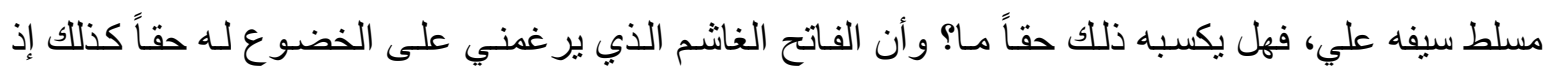
الحق ينتز عه بسلاحه، فالأذى و الجريمة سيان أرتكبهما ملك عظيم و عبد ذليل، فمنصب الجاني و عدد إتباعـه

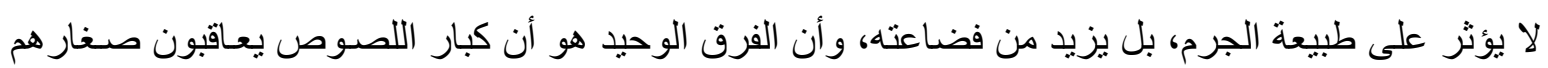
كي ييقو هم على و لائهم لهم، أما الملك فلا يلجأ كهذا اللص في طلب الثـهود أو معاقبة المنحرفين عن و لائهـ في حالة قيامه بالجر ائم، لأنه ليس هناك سلطة أعلى منه، و هذا الفارق بينه وبين كبار اللصوص الذين يعاقبون

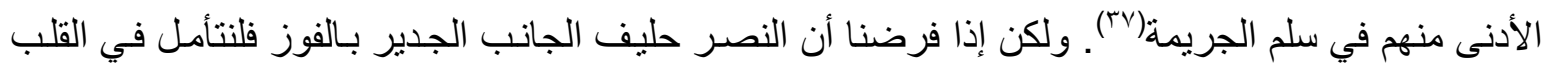
وفي صوب مشرو عاه وننظر ما هي السلطة التي يكتسبها وعلى من؟ ويمكن نوضيح ذلك من خلال : 1 - من الو اضح أنه لا يكتسب أيـة سلطة من جراء غلبته على شركائه في الغلبة. إذ يستحيل أن يلحق بالذين حاربوا إلى جانبه من جر اهها وحري بهم أن ييقوا على الأقل إصراراً كما كانو ا من قبل، و لاسيما أنهم

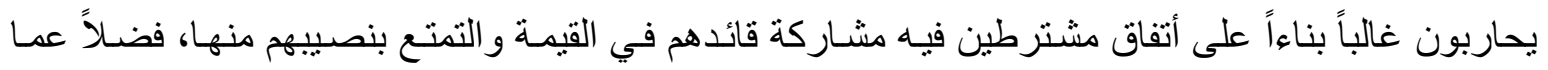
يرجونه من منافع أخرى تجنيها سيوف الفاتحين، و على الأقل من أقطاعات في الأراضي المحتلة و لا يعقل أن

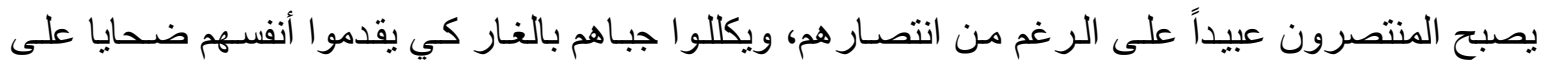


مذبح انتصار قائدهم وحسب(^^). ولكن لنفرض أن الغالب و المغلوب لا يندمجان قط في شعب واحد يعيش في ظل القوانين نفسها ويتمتع بالحرية ذاتها وهي أمر قلما نصادفه. فلنبحث إذاً عن السلطة التي يتمتع بها الغالب على المغلوب، وهي عند جون لوك سلطة استبدادية بحتة("ra).

r- أن الفاتح لا يكتسب السيطرة إلا على الذين ساهموا في استخدام القوة الغاثمة ضده أو و افقو ا عليه أو

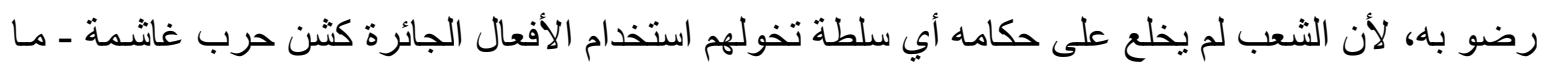
دام لا يملك مثل هذه السلطة ـ- على الرغم من أنه يوجد هنالك قانون يخوله ممارسة هذا الحق(·ء). بـ- أن السلطة التي يحرزها الفاتح على الذين يقهر هم في حرب عادلة هي سلطة استبدادية محضـة، فلـه

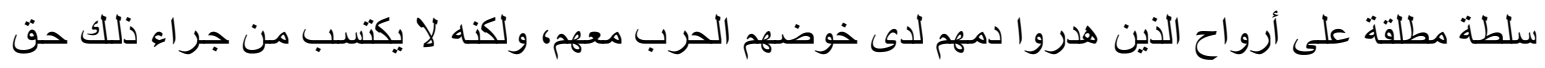
امتلاك أمو الهم فما أكثر ما يتحدث الناس عن الاستيلاء على بلد من البلدان عن طريق الفتح كما لو كان الفتح

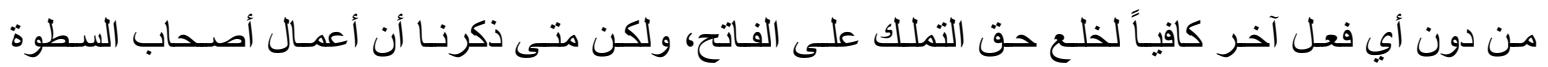
و البطش مهما كانت شـاملة فهي ليست معيار الحق إلا فيما ندر، بانت لنـا صحة ذلك. مـع أن الامتتـاع عن الن مناقتشة الثروط التي تفرضها سيوف الفاتحين مظهر من مظـاهر الخضوع لهم و لا علاقة لـه بـالحق والعدل،

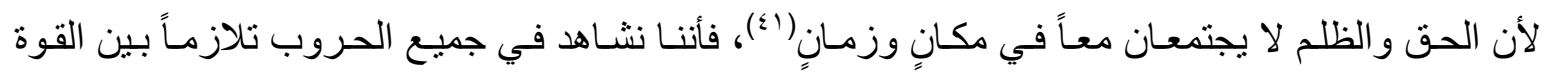
و التخريب، إذ يندر أن يحجم المعتدي عن ألحاق الضـرر بـأملاك الذين يشن عليهم الحرب، ومـع ذللك فأن

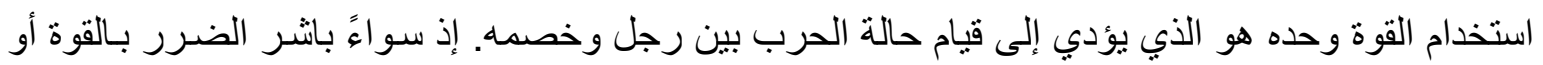

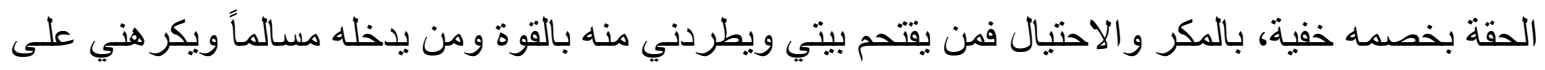

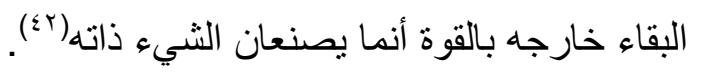

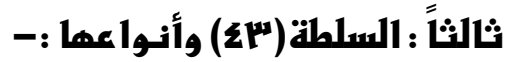

السلطة في رأي جون لوك هي حق وضع القو انين مع العقوبات لتنظيم الملكية والمحافظلة عليها وحق استخدام قوة الجماعة في تنفيذ أمثال هذه القو انين في سبيل تحقيق الخير العـام(؛؛. و أن ماهية توزيع السلطة تفترض تعدد القابضين على السلطة بحيث يقبض على السلطة أكثر من طرف واحد، وتمـارس هذه السلطة الموزعة من قبل جميع القابضين عليها بدون الحاق الضرر بالمصالح المشروعة العامة(؛؛)، ولهذا الفصل و لا

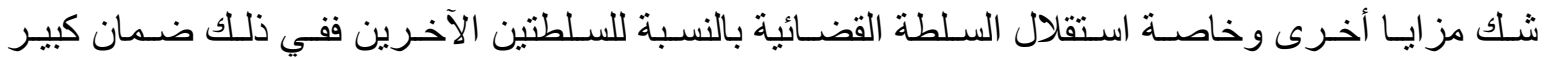
للمو اطنين ضد تعسف الحكام في استعمال سلطتهم، كذلك ازدواج المجلسين في نظر الداعين أليه، فهو بالتأكيد شق المجلس الواحد باندفاعاته(T؟).

وقد ميز جون لوك بين ثلاثة سلطات ((السلطة التشريعية)) التي خصها بأسمى مكان ، (و السلطة

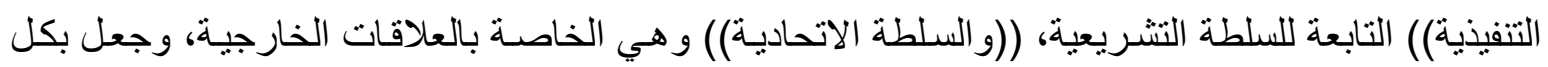

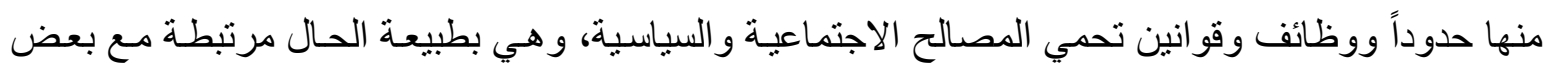
في أهدافها المقصودة حسب نظريـة جون لوك في موضوع السلطة(v؛). فقد كانت السلطة التشريعية تمثنل بالنسبة لجون لوك السلطة الأسمى، حيث يقول جون لوك أن القانون الطبيعي الأول والأساسي الذي يجب أن يحكم كل شيء من المشرع نفسه وهو حفظ المجتمع وكل فرد فيه بقدر اتساقه مـع الصـالح العام، ولهذا فأن 
السلطة التشريعية التي تسن القو انين تمثل السلطة الأسمى، ولكن حتى هذه لا يجب أن تسيء استخدام سلطتها. فهي لا يمكنها أن تتصرف بشكل متعسف فيما يخص حياة الناس ومصير هم و لا يمكنهم عمل أب شيء أكثر

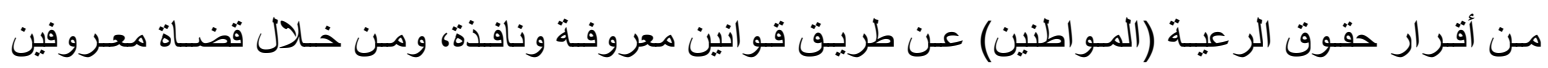
ومفوضين(^)، وفي نظر جون لوك أن السلطة العليا هي التي تضع القوانين، و القوانين هي التي لا يمكن أن تنـال مـن الملكيـات، وأن السـلطة في جوهر هـا هـي سـلطة الحريـة مـن أجل السـعادة، أي أنها حريـة السـعادة بو اسطة العقل، و على هذا الأساس فأن كل سلطة لكي تكون سياسية يجب أن تكون عادلة أو لاً حسب رؤيـة

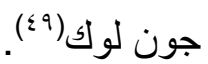

ولهذا فالسلطة التشريعية هي السلطة العليا حسب مـا ير اه جون لوك، لأن من يحق لهه وضع القوانين لمن عداه فهو و لا شك سيد عليهم ولما لم تكن لهذه السلطة الصفة التشريعية للمجتمع إلا بمقدار مـا تملك حق

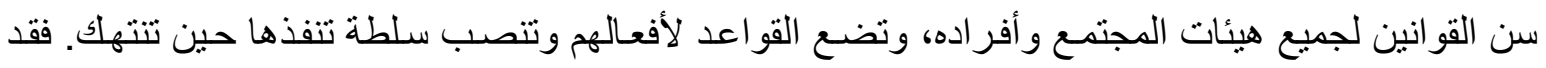
كانت السلطة العليا ضرورة وكانت كل السلطات المسندة إلى أي فرد أو هيئة في المجتمع مستمدة منها وتابعـة لها(·). حيث أن السلطة النشريعية تنعقد انعقاداً مؤقتاً لأنها توضع في أيدي أشخاص مختلفين تكون لهم صلاحية التصرف في الاجتهاد عندما ينعقدون انعقاداً صحيحاً في سن القوانين، فأنهم بعد أن يفعلوا ذلك يتفقوا ثانية حين يصبحون هم أيضاً خاضعين للقوانين التي وضعفها وهو قيد جديد عليهم لضمان أن يضـوا القوانين

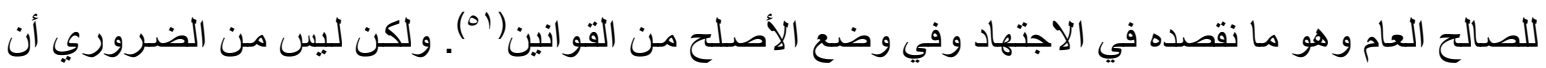

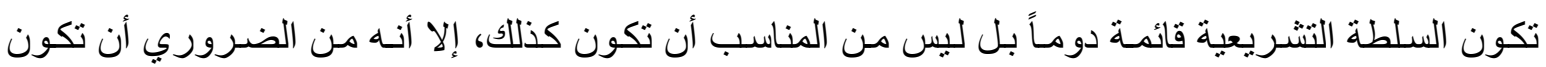

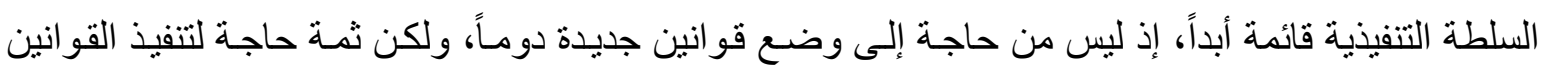
الموضو عة أبداً(مثr)، ونلاحظ أن السلطة التشريعية ليس مطلقة عند جون لوك بل أنها تخضع للقانون، وذللك

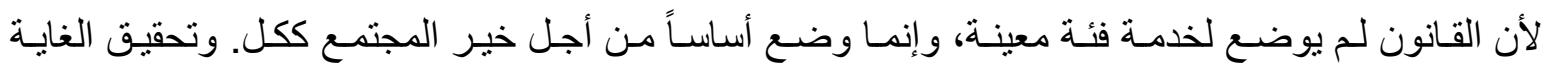
القصـوى مـن تو اجده، إذ بـدون القوانين لا يمكن للمجتهـع أن يتحقق فيـه الخيـر و الرفـاه والصـفاء، وتوزيـع

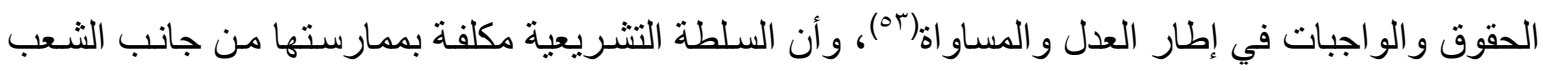
و إذا ما تنازلت عن شيء من سلطتها أو تصرفت خلافاً لمبادئ القانون الطبيعي فمن الممكن عندئذ أن تحل الحكومة من دون أن يؤدي ذلك إلى حل المجتمع و هذا ما يعبر عنه بحق ((الثورة)) ، ولذلك فأن جون لوك من انصار الحكومة المقيدة، ومن القائلين بجواز الثورة على الحكومة إذا استعملت سلطتها في خـارج الحدود

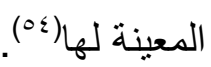

وتأسيساً على مـا تقدم وبحسب جون لوك بأنه لا يحق للسلطة التشـريعية العليا أن تدعي حق الحكم بو اسطة مر اسيم تعسفية مرتجلة، بل يتحنم أن تقر العدالة في حقوق النـاس، بنـاءاً على قوانين مسنونة قائمـة بطبقها قضاة ذو صلاحية معروفون، ولما كانت سنة الطبيعة غير مكتوبـة ولا توجد إلا في أذهان البشر لم يكن من السهل أقناع الذين يخطئون في إير ادها أو تطبيقها لهوى في نفوسهم أو لمصلحة مـا(00)، و هكذا نجد أن ضرورة ألزام المجتمع بوجود القوانين هو الفيصل المشترك بين جميع ثنايا الأفكار و المبادئ التي نادى بها

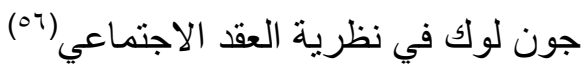




\section{رابـعاً : السلطة الأبوية :-}

يتحدث جون لوك في كتابه المهم ((مقالة في الحكم المدني)) عن دور الأب في الأسرة وهو مصدر السلطة فيها، حيث يعتبر الأب الماللك لأمو اله، و هو القاضي في خصوماتها والداعي لديانتها، و الموقد نار هـا، و القائم بطقوسها وشعائر ها وهو الذي سيصبح بعد موتـه آلهاً يعبد وترتجي روحهـ في طلب الخير و التمـاس

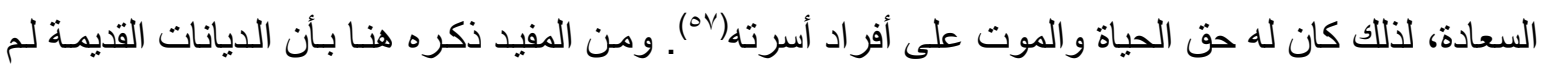
تضع للمرأة مرتبة مثل الرجل، لا تمثنل الأسلاف وليس لها عند موتها عبادة خاصـة. كذلك كانت تعد في الثر ائع الهندية والأغريقية والرومانية قاصر اً على الدوام، ولا يمكن أن يكون لها موقع و لا يحق لها أن تكون رئيسة في المنزل وليس لها سلطة في الأسرة، أمسا بالنسبة للأبناء فكانوا يعدون قاصـرين على الدوام مـا دام أبو هم حياً و هم يخضعون لسلطته(101).

لذلك تعد السلطة الأبوية وبحسب جون لوك بأنها حق إلهي بالسيادة ولا يمكن التغاضي عنه حيث يملك الأب أو الملك سلطة تامة غير محدودة على أرواح أو لاده أو رعاياه وحرياتهم وأملاكهم، حتى أنه يستطيع

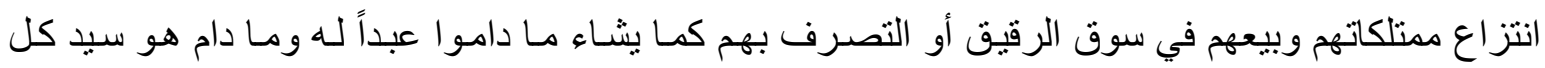

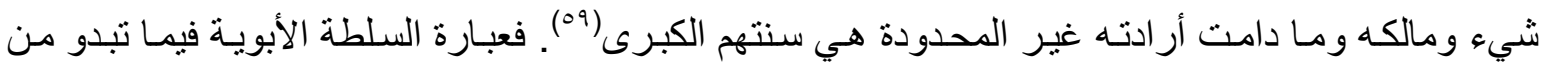
أمر ها أنها تقتصر على الأب وحده كسلطة. كما لو لم يكن للأم نصيب منها، ومع ذلك فنحن بتعبير جون لوك إذا اعتمدنا دليل العقل أو دليل الوصي وجدنا أن لها مثل حق الأب، وهذا مـا يدفعنا إلى التسـاؤل لم لا تدعي تللك السلطة بـ(سلطة الأبوين)، حيث يقول جـون لوك في ذلك أن سلطة الوالدين على الأو لاد تبنى على الو اجب الملقى على عاتقهما وذلك بتعهد بينهما، و العناية بهم في أثناء سنوات الطفولة الناقصـة، فتتقيف عقول البنين القاصرين و الهيمنة على تصرفاتهم وذلك حتى يكتمل إدر اكهم بعدها يرتفع عن كاهل الو الدين عبء هذه

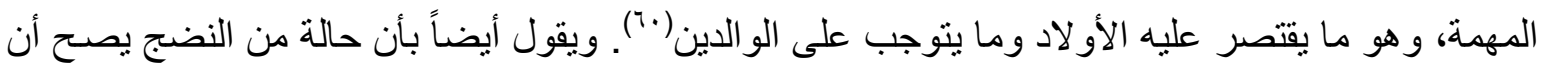

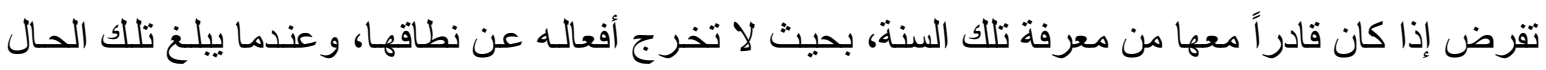

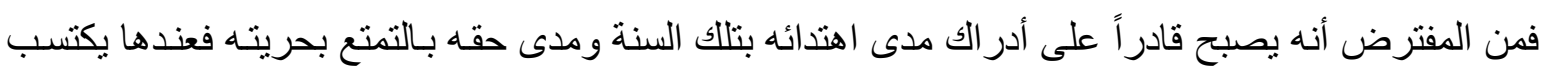

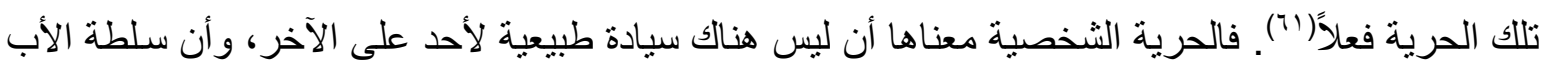
أعطيت له لكي يربي الابن ويجعل منه أنساناً أي كائناً حراً فهي واجب طبيعي، وهي سلطة مؤقتة(rآ). فالحرية الطبيعة لا تنافى مع الرضوخ لسلطة الوالدين بل همـا أمران يستندان إلى مبدأ واحد، فحريـة الولا من حريـة أبيه، و أن إدر اكه الذي ينبغـي أن يهيمن عليه حتى يبلنغ هو سن التمييز، و أن حريـة الرجل

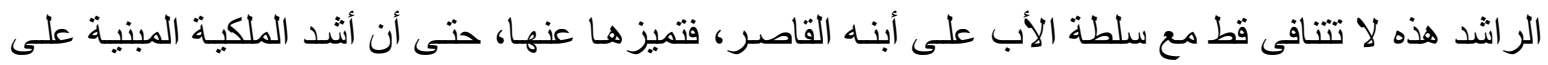

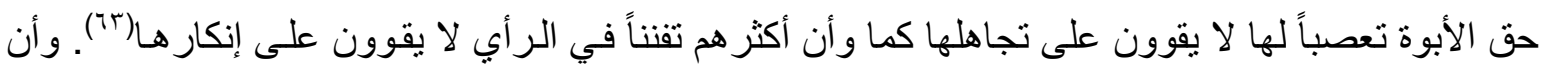

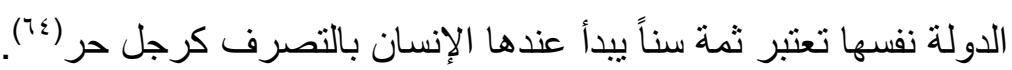

\section{الخاتمة}

لقد تبين لنا من خلال سير البحث، أن لجون لوك طابع خاص في تناوله للفكر الفلسفي السياسي لمـا طرحه من مواضيع اتسمت بالوضوح في تناول عناصره، فقد شرح لنا فيها معتقده ورؤاه لمو اضيع متعددة 
في السياسية والمجتمع استوحاها من ظروفه حصيلته الثقافية، وكذلك بين لنا أن المجتمع لابد لله من قائد يتميز بقيادة كفوءة وصالحة وتنشد العدل والسلام، وإلا فانها تتقلب إلى صورة مشوهة من الفوضى الذي يؤدي إلى الانحلال و الخر اب فيما ير اه هو، ولكن لا ننكر دوره وتأتثيره على الفكر الفلسفي السياسي اللاحق من بعده، حيث احتلت كتبه و آثاره المكانة المتميزة في الدر اسات والبحوث وكذللك في الإطساريح والرسائل التي تناولت فكره السياسي في جامعات العالم، لذلك يعد جون لوك من فلاسفة الفكر السياسي و لابد من مطالعـة أفكاره ودر استها بما تستحق من اعتبار ات فكرية قابلة للتطوير والإبداع الأكاديمي خدمة للعلم و المعرفة.

( (1) العقد الاجتماعي: نظرية في نشوء الدولة والقانون، ترد الاجتماع إلى اتفاق بين الأفر اد، بدخلونهه بمحض أرادتهم، ويتتازلون بمقتضـاها

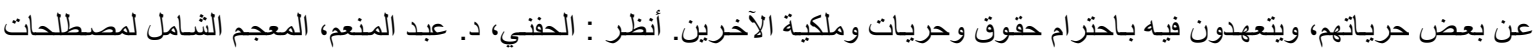

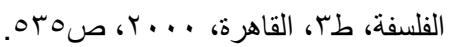

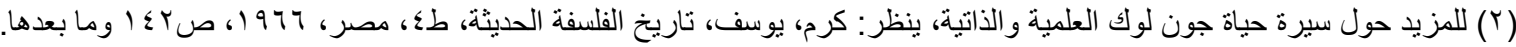

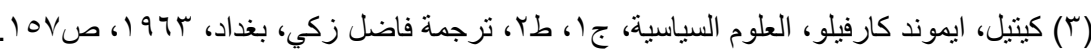

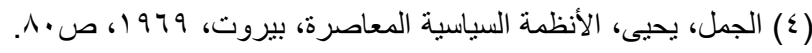

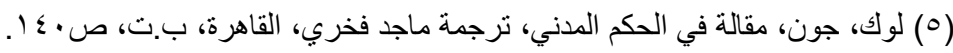

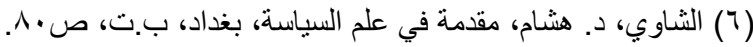

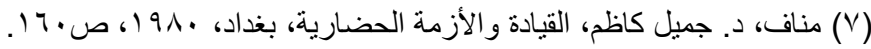

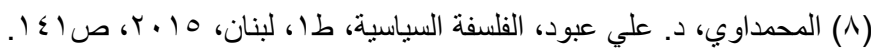

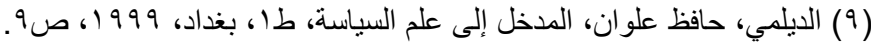

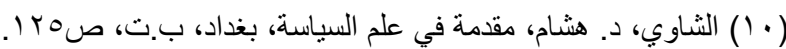

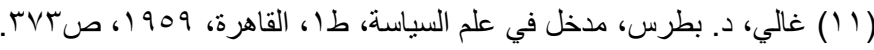

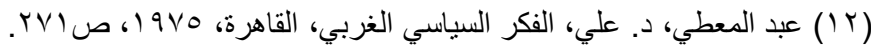

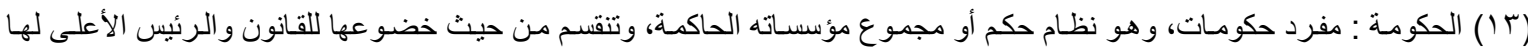

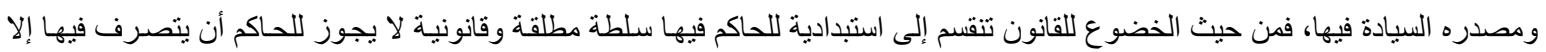

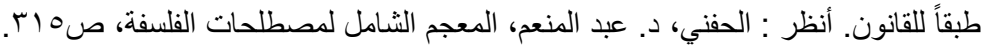

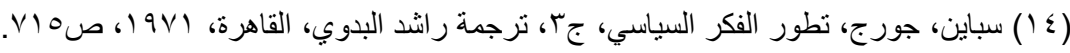

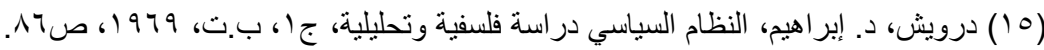

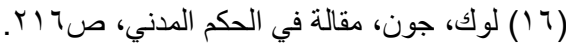

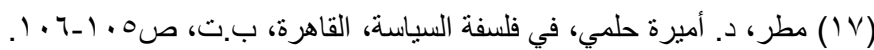

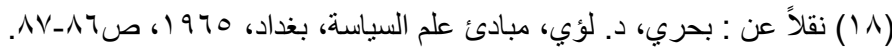

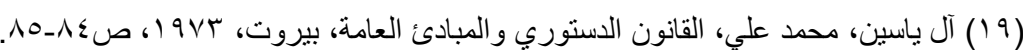

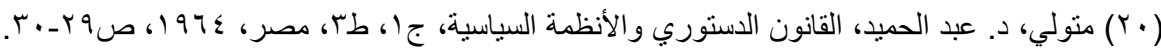

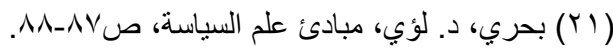

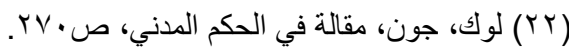

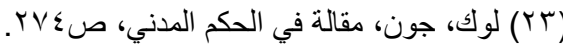

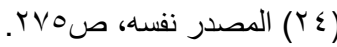

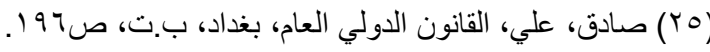

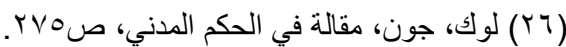

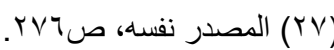


(Y^) الطغيان : في اللغة هو الغلو، و الطاغي هو الظـالم المسرف في الظلم، وهو الجبار المتكبر العاتي، والطـاغوت ـ والجمع طو اغيت ـ

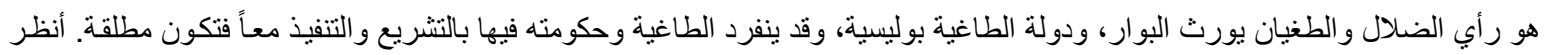

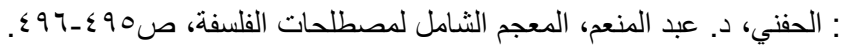

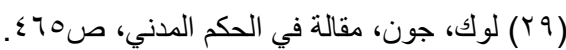

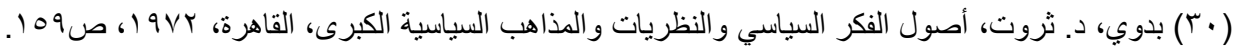

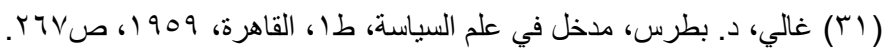

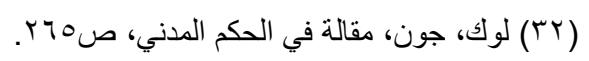

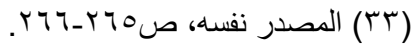

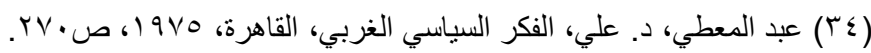

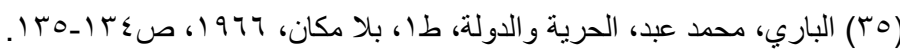

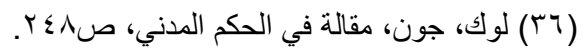

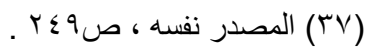

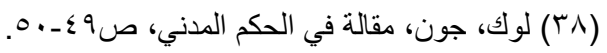

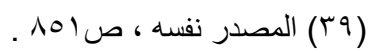

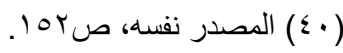

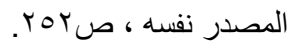

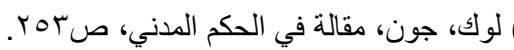

(T؟) السلطة : في اللغة هي التسلط والتحكم، وقد تكون السلطة سياسية أو أدبية أو علمية أو دينية، وقد تكون سلطة تشريعية كما يبدو للبعض

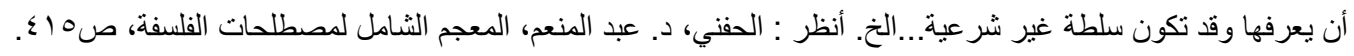

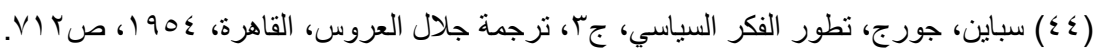

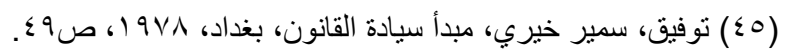

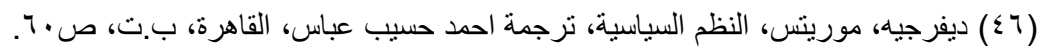

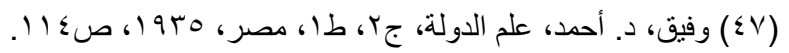

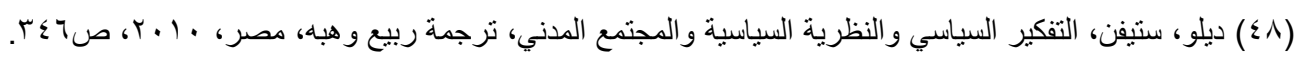

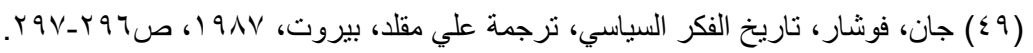

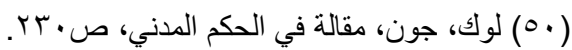

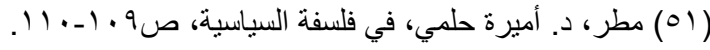

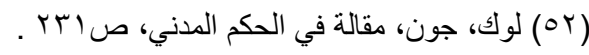

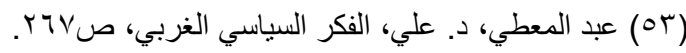

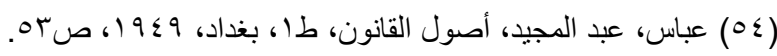

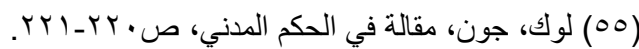

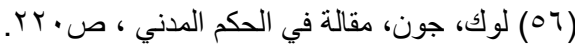

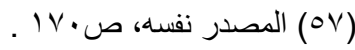

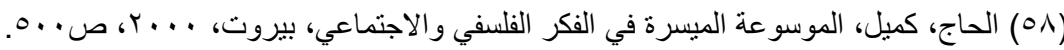

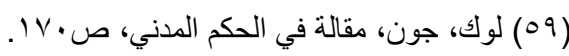

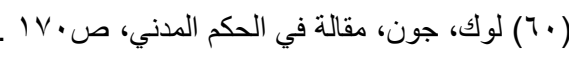

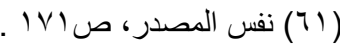

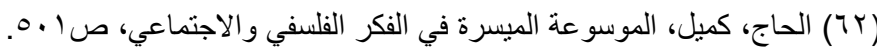

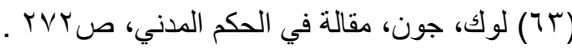

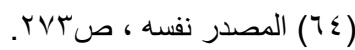


قائمة بأسهاء المادر والمراجع:

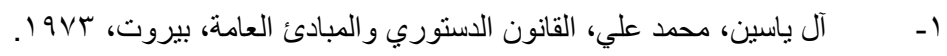

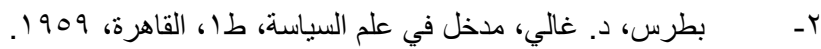

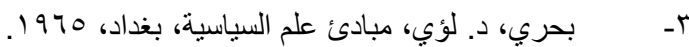

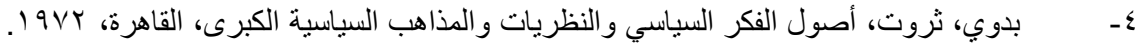

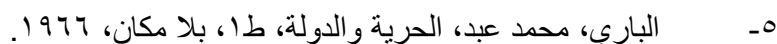

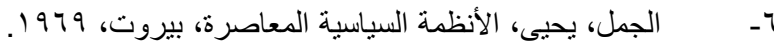

جان، توشار، تاريخ الفكر السياسي، ترجمة علي مقلد، بيروت،

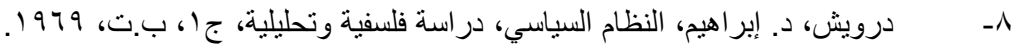

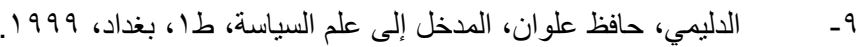

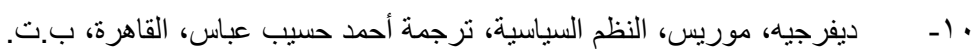

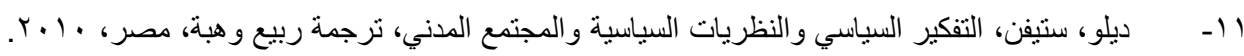

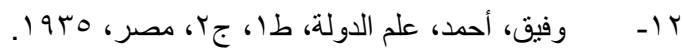

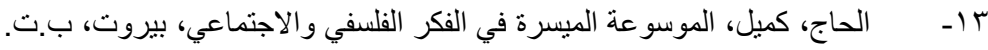

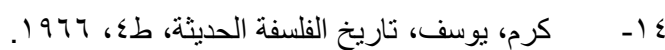

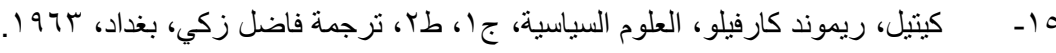

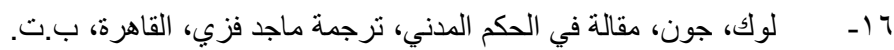

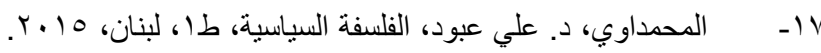

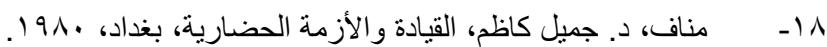

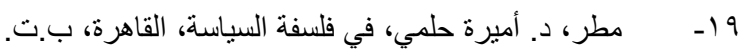

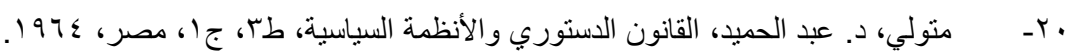

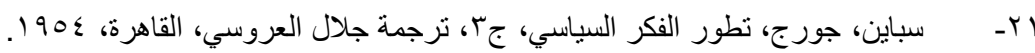

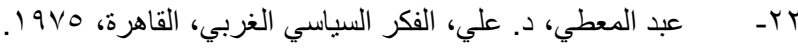

rr

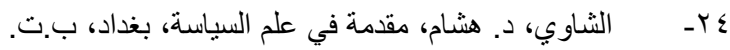

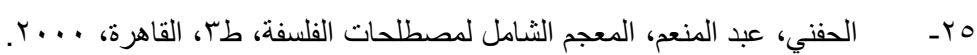

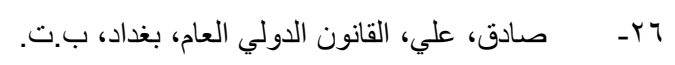

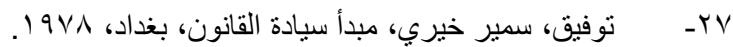

